\title{
Sexual and reproductive health problems and service needs of university students in south east Ethiopia: Exploratory qualitative study
}

\author{
Tesfaye Setegn Mengistu*, Abulie Takele Melku \\ Department of Nursing, College of Medicine and Health Sciences, Madawalabu University, Ethiopia \\ Email address: \\ tesfayesetegn@yahoo.com(T. S. Mengistu), abuletakele@yahoo.com(A. T. Melku)
}

\section{To cite this article:}

Tesfaye Setegn Mengistu, Abulie Takele Melku. Sexual and Reproductive Health Problems and Service Needs of University Students in South East Ethiopia: Exploratory Qualitative Study. Science Journal of Public Health. Vol. 1, No. 4, 2013, pp. 184-188. doi: $10.11648 /$ j.sjph.20130104.13

\begin{abstract}
In developing countries, youths have been disproportionately affected by reproductive health problems due to their risky behaviors. Reproductive health problems have been prominent in areas where large youth population found. Therefore, this exploratory qualitative study has assessed sexual and reproductive health problems and service needs of university students. In this study, majority of students don't have adequate awareness on sexual and reproductive health risks and have exhibited high risk reproductive health behaviors. Although, there are immense and diversified sexual and reproductive health problems, health care services utilization was negligible. Lack of information about available health services and absence of specific services that meet the needs of youth were the major reported reasons for low sexual and reproductive health service utilization. Therefore, comprehensive sexual and reproductive health services giving emphasis to peer education, IEC and/or BCC trainings, establishing SRH/HIV/AIDS resource center and making the university clinic youth friendly are recommended interventions.
\end{abstract}

Keywords: Exploratory, Sexual Health, Reproductive Health, Risks, Students

\section{Introduction}

Youth/adolescence period is a time of transition to adulthood. During this period new behaviors are more easily learned than in adulthood. Worldwide more than one billion people are between 15-24 years of age. Most of the world's youth are living in developing countries. Currently, young people in the age group 10-24 years accounts over 30\% of the world's total population $(1,2)$. Adolescence period is characterized by immature, exploration and experimentation behaviors of adolescents and subjection to peer influences. When viewed from various behavioral, cognitive and developmental perspectives, young people can be labeled as the vulnerable group; because this segment of population is threatened by sexual and reproductive health problems. These days, most young people are exposed to risky behavioral practices in their teens. Moreover, negative behavioral practices during adolescence period predispose adolescents to sexual and reproductive health problems (3, 4).

Adolescents have been exposed to various sexual and reproductive health $(\mathrm{SRH})$ problems because of their risky sexual behaviors without necessary precautions. Particularly these days, young people are highly suffering from the tragedy of HIV/AIDS. Millions of young people have been infected with HIV and millions of them have died of it. Adolescent females have been jeopardized by the pandemic and other reproductive health risks such as unwanted teenage pregnancy, unsafe abortion-related complications, and dropout from schools (5-8).

In general, youths often lack access to health information and health care services. As well they have been characterized by low sexual and reproductive health service utilization due to feelings of discomfort, fear of being seen by parents and others while they are in health care delivery points, embarrassment while seeking reproductive health care services $(9,10)$.

In Ethiopia, over $65 \%$ of the population is under 25 years of age. Ethiopia is a nation whose youth have profound reproductive health needs and are disadvantaged in their access to sexual and reproductive health information and services. Gender inequality, sexual coercion, early sexual debut, unwanted/unplanned adolescent pregnancy, abortion, 
sexually transmitted infections and HIV/AIDS are the major sexual and reproductive health problems in Ethiopia. Different factors for sexual and reproductive health problems have been operating at individual, peer, family and community level $(9,11)$.

Although Ethiopia has developed a national youth policy in 2004, yet much is expected to the provision of reproductive health care to university/college students (12-16). Adequate systems such as, information education communications(IEC), appropriate guidance and counseling services are not yet rendered to deal with students' sexual and reproductive health problems which might be due to paucity of research findings.

Therefore, this study was aimed to systematically explore young people's sexual and reproductive health problems, reproductive health service needs and utilization among Madawalabu university students.

\section{Methods}

\subsection{Study Setting}

An exploratory qualitative study was conducted in Madawalabu University from May - Jun 2011/12. Madawalabu University is one of the higher education institutes in Ethiopia established in 2007. This university is located in Bale Zone which is the second largest Zones in Oromiya region; South East Ethiopia located $430 \mathrm{KMs}$ from Addis Ababa. The temperature ranges from $3.5^{\circ} \mathrm{C}-32^{\circ} \mathrm{C}$. The Zonal altitude varies from $300 \mathrm{~m}$ to $4377 \mathrm{~m}$ above sea level. Bale Zone is known to its eye catching natural and tourist appealing geographic sites like the Bale Mountain Park and Sof-Omar Cave. There are three district hospitals rendered to provide both preventive and curative health services.

The university has two campuses namely Bale Robe campus (main campus) and Bale Goba (College of Medicine and Health Sciences) campus. Currently there are over 490 academic staffs and more than 5,270 regular students enrolled in 34 departments.

\subsection{Study Participants}

Randomly selected schools from both campuses were included in the study. The school directors, student service director, director of gender affairs office, staffs from students' clinic, female academic staffs, proctors (dormitories), students (both sexes), members of student council and university guards were participated in the study.

A total of seven sex disaggregated focus group discussions (FGD)-consisting of eight participants- and nine in-depth interviews were conducted. Focused group discussions were carried out with randomly selected students and university clinic health care providers while the in-depth interviews were done with purposively selected university officials and school directors.

\subsection{Data Collection Procedure}

Data were collected using semi-structured open-ended interview guide (17). In-depth interviews and focused group discussions were conducted by trained interviewers, facilitators and note takers. The interviews and discussions were held in Amharic language. In order to make the environment easy for participation and discussion participants were sex disaggregated. The overall data collection process was thoroughly controlled. The full interviews and discussions were tape-recorded and notes were taken during discussions. The principal investigator had kept diary of the field experiences and reflections.

\subsection{Data Analysis}

Data were transcribed in to an English text by replaying the recorded interviews and discussions. Point of idea saturation was the assurance to end the in-depth interview and focus discussion. Concepts were merged in their thematic areas and a manual thematic framework analysis was employed. The results were summarized and presented in narrative forms.

\subsection{Ethical Consideration}

The proposal was ethically approved by Madawalabu University Research and Community Service Office. Letter of cooperation was submitted to respective school directorates. All of the study participants were informed about the purpose of the study and oral consent was obtained before participation. Respondents were also notified that they have the right to refuse or terminate at any point during the interview and discussion. They were also assured on the confidentiality of information they provided. Participants were assured that they would not face any harm due to their participation in the study.

\section{Results and Discussion}

A total of 7 focused group discussions in the two campuses (FGD) (including 1 FGD with the university clinic staffs) were carried out with a total of 52 participants (24 male and 23 female students). Additionally, 9 in-depth interviews were conducted with randomly selected academic school directors. Purposively selected director, officers, staff representatives, university guards and proctors were also interviewed for scientific consideration (Table-1 \& 2).

Table 1 Characteristics of focused group $(F G D)$ discussants $(N=52)$

\begin{tabular}{llll}
\hline Characteristics & $\begin{array}{l}\text { Campus } \\
\text { Robe }\end{array}$ & Goba & Total \\
\hline $\begin{array}{l}\text { Age of the } \\
\text { discussants }\end{array}$ & mean=21.6yrs,SD=2.6 yrs & \\
Sex of students & & & \\
Male & 16 & 8 & 24 \\
Female & 16 & 7 & 23 \\
Health care providers & 5 & 0 & 5 \\
\hline
\end{tabular}


Table 2 Characteristics of in-depth interview participants $(N=9)$

\begin{tabular}{llll}
\hline Characteristics & $\begin{array}{l}\text { Campus } \\
\text { Robe }\end{array}$ & Goba & Total \\
\hline Directors & 4 & 0 & 4 \\
Officers/staffs & 2 & 0 & 2 \\
Others* & 3 & 0 & 3 \\
\hline
\end{tabular}

* University guards and proctors

Reasonably detailed information on understanding about reproductive health, existing sexual and reproductive health problems, (including risk behaviors, low awareness/knowledge, STIs and HIV infection, unwanted pregnancies and its consequences, substance use), reasons that expose students for sexual and reproductive health problems, reproductive health service utilization and felt health services need and suggested solutions were addressed. For this particular exploratory qualitative study, participants had reported their real life experiences and observations.

\subsection{Understandings about Sexual and Reproductive Health}

With minimal individual differences in understanding reproductive health and related issues, students, health professionals and in-depth interviewees ordinarily believed that sexual and reproductive health problems are rampant in the two campuses. Female and male students have different levels of understandings. Almost all students defined reproductive health in association with women's health. Few discussants define reproductive health in views of sexual and reproductive health risks such as unwanted pregnancy, STIs/HIV, gender based violence (GVB). Although discussants from health science campus gave more formal definition of reproductive health, generally students' actual knowledge about the reproductive health was found to be superficial and inadequate.

The primary reason for such inadequate understanding on sexual and reproductive health could be due to the absence of awareness rising session in the campuses so far. A remark made by female student focused group discussants is illustrative for this situation; “... nothing! No information was given to raise the awareness of students in this regard [sexual and reproductive health]".

Additionally, absence of information resource center which would be responsible for the delivery of updated and reliable information and education on sexual and reproductive health issues to university adolescents is absent. This can be substantiated by the remarks made by a school director as: "...in our university there no access to health information with regards to this 'guday' [issue] [sexual and reproductive health]" while a university clinic staff repeated this issues in a similar expression as: "... health information, which may bring behavioral change like abstinence, faithfulness and use of condom could have paramount importance in addressing these problems but nothing was done".

\subsection{Magnitudes of Sexual and Reproductive Health Problems}

Regarding to the magnitude of sexual and reproductive health problems in the campus, almost all focused group discussant discussants and in-depth interview participants claimed that it is a serious problem. Risk behavior (such as substance use /alcohol consumption, multiple sexual partners, early sexual initiation...etc), low awareness/knowledge, STIs/HIV infection, unwanted pregnancy/abortion and gender based violence/sexual harassment were the identified themes of sexual and reproductive health problems and prevailed in the university community.

Risky sexual behaviors that might practice due to low awareness and/or low knowledge are the perceived sexual and reproductive health problems on students. Discussants affirmed that those who have lack of awareness and/ or low knowledge about sexual and reproductive health related issues are highly likely to face sexual and reproductive health problems easily. Lacks of assertiveness, practicing unsafe sex, having multiple sexual partners and ever increasing trend of substance are apparent risks of sexual and reproductive health problems.

The overall magnitude of sexual and reproductive health problems could be better elucidated by a statement given by a clinic staff as: “... almost all students do have awareness about the problems of STIs/HIV infection but they initiate sex early due to myths and misconceptions about campus...they do not put the information they have into practice".

Majority of students have practiced risky behaviors which may be supported by a stamen made by a female student [focused group discussant]; "...unsafe sex, I think it is common and the trend has been changed!" This might happened due to the students unhealthy behaviors as remarked by a university guard saying; “...some students come late almost in the mid night...drunk and shouting... even female students".

Although some focused group discussants and in-depth interviewee reflect some difference regarding the presence of risk reproductive health outcomes such as unwanted pregnancy, abortion, STIs/HIV infection, most participants unreservedly reflected that they are serious problems affecting university students. In this regard a female focused group discussant said; "...there are unwanted pregnancies. For example last week two students gave birth in the campus. This was very strange and seems impossible”. In a similar way, a male participant stated as: "...I heard that there were two abortion cases in the campus which might indicate abortion in our campus is an open secret".

Concerning the factors predisposing university student to sexual and reproductive health problems, university clinic staffs and director/officers consistently stated that economic problems, peer pressure, absence of preventive intervention and lack of access to information education communication (IEC) on sexual and reproductive health (SRH) issues were 
reported to be significant reasons for the problems. Regarding peer pressure a clinic staff stated as; “...peer influence is an important factor for female students to be engaged in to sexual activities...it is difficult..." in the other way round, most participants echoed the presence of apparent sexual harassment cases on female students which can be clarified by statement made by a female focused group discussant as: "...regardless of the perpetrators, sexual harassment is not uncommon and is worsening in our campus... through forcing female students to have sex ....".

In addition, student participants disclosed that there are consensual types of sexual relationships which could not be regarded as sexual harassment. Contradicting the students' idea, some in-depth interviewee denied the existence of sexual harassment giving "no data or evidence" as a means of refuting.

Few participants equate sexual harassment with rape and they do not consider sexual harassment unless rape is taken place. Regarding the common perpetrators, some focus group discussants reported that most students and some undisciplined teacher harass female students. This finding can be backed up by a statement of a male focused group discussant saying; ".... a female student has dismissed from the university because she refused to have sexual relation with her teacher". But in some cases, participants reported that female students might have taken the initiative of having sexual relation with few teachers with their hidden agenda-just to have sex in exchange of marks.

Majority of participants agreed that female student especially those from rural areas, students living outside the campus, new comer student, academically poor (low achiever) students are the most victims of reproductive and sexual health problems and gender/sexual harassment related problems. Lack of provision of health information to reduce students' risky behaviors, peer pressures, absence of counseling and guidance service, absence of parental control, lack of assertiveness, poor academic achievement, myths and misconceptions about campus life and sexually explicit films were important and reported reasons that exposed students to have sexual and reproductive health as well gender based problems.

Although sexual and reproductive health problems are abundant, students are still less likely to use the university clinic which might be due to the lack of assertiveness to decide on healthy sexual and reproductive health matters. In this regard, a female nurse made an illustrative point as saying: "...there is a problem of being confidents enough to seek reproductive health care services". Likewise, female focused group discussants reported that majority of students prefer remaining silent and in some cases they will seek help from their friends. An experience noted by a female participant as; "...students do not want to seek care for their SRH problems. For example for the last case of abortion (happened in dormitory) the student simply complains abdominal pain and it took place in dormitory".

From the qualitative nature of this study, we were able to capture the true image of the sexual and reproductive health problems and possible reasons of predisposing factors. The trustworthiness of information was assured by interviewing individuals and groups from different target population. But this study is unable to quantify the magnitude of sexual and reproductive health problems and risks. So, interpretation and generalization should take the strengths and weakness in to account.

\section{Conclusion}

This study has revealed that students' understanding/perceptions on sexual and reproductive health issues and its consequences are superficial. Students in African universities lack information on the extent and impact of the HIV infection on campus (18). In this study, students do not have appropriate awareness on intricate nature of sexual and reproductive health matters which might be due to lack adequate and pertinent health information, counseling and guidance on these matters to bring healthy behavior changes.

It is evidenced that students have inadequate and fragmented knowledge on sexual and reproductive health problems. As a result, most of them are not sufficiently skilled in making informed and responsible decisions to minimize their involvement in risky sexual practices (such as early sexual initiation, having multiple sexual partners, in- consistent or non-use of condom and low use of contraceptives) to stay healthy. Considerable numbers of students have been exhibiting high risk reproductive health behaviors that would predispose them to reproductive health problems. Wide variety of high-risk activities and arrangements, sexual experimentation, practicing sex for any kind of benefits (in kind/cash), unprotected casual sex, frequent partner change, and considerable physical and psychological violence against female students are prominent predisposing factors.

This study also has indicated that, young people's sexual and reproductive health information and services utilization are significantly low which might have fueled the occurrence of sexual and reproductive health problems.

\section{Recommendations}

The risks for reproductive health problems need urgent and tailored interventions. The high-risk behaviors being practiced by university students in the context of very low health service seeking and utilization pattern signals promoting integrated youth-friendly intervention programs. Therefore, establishing youth friendly service, rendering STIs, HIV/AIDS and SRH resource center which would be responsible for continuous IEC provision and instituting counseling service are recommended.

\section{Authors' Contributions}

TS conceived and designed the study, performed analysis 
and interpretation of data and drafted the manuscript. AT assisted with the design, conception, analysis, and critically reviewed the manuscript. All authors read and approved the final manuscript.

\section{Acknowledgements}

We are grateful to Integrated Family Health Program (IFHP) for its technical support and its staffs for their encouragement. We would like to extend our appreciation to Madawalabu University, for providing the necessary information and facilitating conditions while carrying out this study. We are also very grateful to extend our appreciation to the study participants who share their priceless time and the data collectors for their full commitment, participation and technical support.

\section{References}

[1] UNICEF, youth health for a challenge, note book on programming for young people's health and development; 1997.

[2] Federal Democratic Republic of Ethiopia, MOH. National youth and Adolescent reproductive health strategy; 2006.

[3] Friedman LH, Edstron GK. Adolescent Reproductive Health: an approach to planning health services research. WHO, Geneva; 1983.

[4] WHO. Programming for adolescent health and development. Report of WHO/UNFPA/UNICEF study group on health programming for adolescents. Technical report series No. 886. WHO, Geneva; 1999.

[5] WHO. Child and Adolescent Health and Development: progress report 2002-2003; 2004.

[6] UNAIDS. Children and young people in a world of AIDS. Geneva; 2001.
[7] UNICEF joint UNAIDS and WHO. Young people and HIV/ AIDS: Opportunity in crisis; 2002.

[8] UNFPA. Adolescent Reproductive Health: Making a difference; 1999.

[9] FHI/Youth Net. Assessment of youth reproductive health programs in Ethiopia. Addis Ababa, Ethiopia: Family Health International; 2004.

[10] Chen B, Lu YN, Wang HX, et.al. Sexual and reproductive health service needs of university/ college students: updates from a survey in Shanghai, China. Asian J Androl 2008; 10 (4): $607-615$.

[11] Abubeker A. Youth reproductive health problems and service Preferences in Assebe Teferi, West Hararghe. (MPH Thesis) Department of Community Health, Faculty of Medicine, Addis Ababa University, 2004.

[12] Bin Chen, Yong-Ning Lul, Hong-Xiang Wang, et.al. Sexual and reproductive health service needs of university/ college students: updates from a survey in Shanghai, China. Asian $J$ Androl 2008; 10 (4): 607-615.

[13] Laura S. Reaching the youngest Adolescents with Reproductive health programs. Focus on Young Adults, 2000; URL; httip://www.pathfind.org/focus

[14] UNAIDS. Report on the global AIDS epidemic: $4^{\text {th }}$ global report; 2004.

[15] UNFPA. Preventing HIV/AIDS among adolescents through integrated communication programs. New York; 2004.

[16] MOH. Five-Year Action Plan for Adolescent Reproductive Health in Ethiopia. MOH, Family Health Department. Addis Ababa, Ethiopia; 2002.

[17] Ethiopian Public Health Association (EPHA). Young People's HIV/AIDS and Reproductive Health Needs and Utilization of Services in Selected Regions of Ethiopia; 2005.

[18] Federal Democratic Republic of Ethiopia. Policy on HIV/AIDS of Federal democratic Republic of Ethiopia. Addis Ababa, 1998. 